\title{
Application of an Evaluation Framework for Extra-Organizational Communities of Practice: Assessment and Refinement
}

\author{
Kaileah A. McKellar, Whitney Berta, Rhonda Cockerill, Donald C. Cole \\ University of Toronto \\ Johanne Saint-Charles \\ Université du Québec à Montréal
}

\begin{abstract}
Communities of practice (CoPs) are groups of people who work together on an ongoing basis and share knowledge and expertise. CoPs exist both within and outside of organizations, although extra-organizational CoPs have received less evaluation attention. The primary objective of this study was to assess the applicability of a multi-level, multiple-value evaluation framework for extra-organizational CoPs. Qualitative interviews were conducted with an extra-organizational CoPthe Canadian Community of Practice in Ecosystems Approaches to Health (CoPEHCanada). The evaluation framework oriented both the member interview guide and the deductive content analysis. The findings showed that the evaluation framework was sufficiently comprehensive to capture the values generated. Following reflection on these findings, challenges in its application and suggested revisions to the framework are provided; also discussed are limitations and strengths, evaluation research next steps, and the opportunities for future applications.
\end{abstract}

Keywords: capacity strengthening, communities of practice, evaluation framework, qualitative, value creation

Résumé : Les communautés de pratique (CdP) sont des groupes de personnes travaillant ensemble de façon continue et mettant en commun leurs connaissances et leur expertise. Bien que les CdP existent tant au sein des organisations quả lextérieur de celles-ci, les CdPs extraorganisationnelles ont reçu relativement peu diattention en matière dévaluation. L’objectif principal de l'étude était deévaluer l'applicabilité d'un cadre dévaluation multiniveaux tenant compte de plusieurs valeurs pour les $C d P$ extraorganisationnelles. Nous avons mené des entrevues qualitatives avec des membres d'une communauté de pratique extraorganisationnelle, la Communauté de pratique en approches écosystémiques de la santé (CoPEH-Canada). Le cadre d'évaluation a aiguillé autant le guide d'entrevue des membres que l'analyse de contenu. Nos résultats ont montré que le cadre d'évaluation était suffisamment complet

Corresponding author: Kaileah A. McKellar, Institute of Health Policy, Management and Evaluation, University of Toronto, 155 College Street, Toronto, ON M5T 3M7; Kaileah. mckellar@mail.utoronto.ca 
pour tenir compte des valeurs générées par la CdP. Après réflexion, nous avons noté certains défis dans la mise en œuvre du cadre, qui nous conduisent à y suggérer des révisions. En conclusion, nous discutons des limites et des points forts du cadre ainsi que des pistes de recherche et de mise en cuvre qui se dégagent de notre analyse.

Mots clés : amélioration de la capacité, communautés de pratique, cadre d'évaluation, qualitative, création de valeur

Communities of practice (CoPs) have drawn the interest of scholars and practitioners, as their contributions are increasingly acknowledged in healthcare, education, and business. Understood in an instrumental sense, CoPs can be defined as groups of people who work together on an ongoing basis and share knowledge and expertise. While CoPs can form without external support, many funders are supporting or facilitating CoPs as a way of promoting knowledge generation (Amin \& Roberts, 2008), stimulating innovation (Wenger, McDermott, \& Snyder, 2002), providing practical guidance (Brown \& Duguid, 1991), sharing tacit knowledge (Buckley \& Du Toit, 2010), socializing new members to a field (Lave \& Wenger, 1991), or addressing system change (Kothari, Boyko, Conklin, Stolee, \& Sibbald, 2015). Despite these potential benefits of CoPs, there has been limited focus on appropriate evaluation frameworks (McKellar, Pitzul, Yi, \& Cole, 2014) or evaluation of their effectiveness (Barbour, Armstrong, Condron, \& Palermo, 2018). This study aimed to address this gap.

There are multiple types of CoPs; different typologies characterize relevant distinctions among them. One meaningful way to characterize CoPs is by organizational setting, as it can contribute to their goals, types of support received, and evaluation priorities. As such, a distinction can be made between intraorganizational, inter-organizational, and extra-organizational CoPs (McKellar, 2019). Although extra-organizational research networks have received substantial attention (Contandriopoulos, Larouche, \& Duhoux, 2018), extra-organizational CoPs have been relatively neglected by scholarly evaluators.

To address this gap, McKellar (2019) developed a new evaluation framework for extra-organizational CoPs. The framework scaffolds around two dimensions: types of value that can be experienced through CoP processes; and multiple levels of analysis (e.g., members, stakeholders) that experience these values (see Tables 1 and 2 below, and definitions in the Appendix). The evaluation framework uses the term "value," as it encompasses processes and outcomes of CoPs and reflects the language of Wenger, Trayner, \& de Laat's (2011) Value Creation Framework, from which the types of value were adapted.

The objective of this study was to assess the applicability of this framework with members of an extra-organizational $\mathrm{CoP}$ through a qualitative approach. Specifically, the article addresses the following question: How well do the dimensions of the evaluation framework help to capture the value created by extra-organizational CoPs? After introducing the methods, we describe how values generated at the individual and collective levels fit with the framework. We then describe the challenges encountered in this application and subsequent refinements made to the 
evaluation framework. We conclude with a discussion of limitations and strengths in our approach and future directions.

\section{METHODS}

\section{Evaluation case for application of the framework}

The extra-organizational CoP studied was the Canadian Community of Practice in Ecosystem Approaches to Health (CoPEH-Canada), founded in 2008. As a CoP, CoPEH-Canada "share[s] a basic body of knowledge that creates a common foundation, allowing members to work together effectively" (Wenger et al., 2002, p. 66) and has a "commitment to exploring the domain and to developing and sharing relevant knowledge" (p. 43). CoPEH-Canada is committed to the development and dissemination of ecohealth ideas and practices. As described by Charron (2012, p. 7), ecohealth (i.e., ecosystem approaches to health) "recognizes that health and well-being are the result of complex and dynamic interactions between determinants, and between people, social and economic conditions, and ecosystems." CoPEH-Canada aims to address current challenges to a healthy and sustainable global future by supporting collaboration, capacity building, education, and knowledge translation. Members include practitioners, policymakers, and many academics in a dispersed nodal structure; the three nodes are Western, Ontario, and Québec-Acadie-Atlantique. As CoPEH-Canada has been supported through grant-based funding, core members of the $\mathrm{CoP}$ tend also to be principal investigators, often one per node. These core members are located at nine Canadian universities in five provinces.

Among the training and capacity-building activities was a collectively designed, intensive field course offered to graduate students and professionals to strengthen collaborative capacities (Parkes et al., 2017). Over its first decade, $\mathrm{CoPEH}$-Canada expanded to include many field-course participants. Additional activities have included core team meetings to coordinate and provide strategic direction for the community of practice, including sustainability planning. CoPEH-Canada has also partnered with the Latin American Community of Practice (CoPEH-LAC), forming EkoSanté, which aimed to learn from past ecohealth experience (Brisbois et al., 2017) and to support emerging scholars and nodal activities.

CoPEH-Canada had evaluated some educational activities (Parkes et al., 2017) but continued to face unanswered evaluation questions (Parkes, Charron, \& Sánchez, 2012). Given that characteristics and activities of CoPs change with stages of maturity (Lee, Suh, \& Hong, 2010), CoPEH-Canada's relatively long trajectory meant that it had potentially generated a range of values considered in the proposed evaluation framework. Furthermore, the primary author (KM) participated in CoPEH-Canada, as did two of the contributing authors (DC, JSC), one as a founding member (JSC). This provided access to interview participants and contextual understanding of the interview data. 


\section{Methodological approach}

Qualitative methods are well aligned with a conceptual approach to evaluation, which incorporates interactive, social, and dialogic learning (Schwandt, 2003), appropriate to a CoP (Lave \& Wenger, 1991). This more dialogical approach is closely aligned with CoP concepts (Chouinard, 2013), such as situated learning (Lave \& Wenger, 1991). Through qualitative interviews that ask members about their experiences in the $\mathrm{CoP}$ and potential value generated by involvement in the CoP, we could assess whether the evaluation framework captured such value for CoP members.

\section{Data collection}

The sampling frame comprised registered members of CoPEH-Canada who participated in at least one of the annual CoPEH-Canada field schools, as either student participants or part of the teaching team $(n=191)$. Early-career members included students, postdoctoral fellows, or early-career professionals at the time of their participation, some of whom had advanced in their careers since course participation (as early as 2008). Later-career members had more established academic careers at the time of participation.

The sampling strategy was purposive (Teddlie \& Yu, 2007), aiming to obtain views from a variety of members with different characteristics. Both early- and late-career participants within CoPEH-Canada were selected from different geographic regions, with varying lengths of time participating in the community, and core and peripheral status, as judged by the three CoPEH-Canada co-authors. The number of interviews was determined ultimately based on code saturation (Hennink, Kaiser, \& Marconi, 2017) at the individual and collective levels.

Fifteen semi-structured interviews were conducted, face-to-face when feasible (3), or by Skype or telephone when face-to-face was not feasible (12). Interviews were conducted primarily in English, with native French speakers (3) encouraged to switch to French at any point during the interview if they felt more comfortable or were better able to express themselves. Passive bilingualism, where people respond in their preferred language, is common in CoPEH-Canada. Interview recordings ranged from 20 to 77 minutes, with an average length of 48 minutes. Each participant was interviewed once, though they were available for subsequent clarifying conversations (none needed).

The interviews started by asking the member about their professional background and participation in CoPEH-Canada (guide available upon request). Informed by the evaluation framework, they then moved to questions based on the levels of analysis (individual, collective, etc.), using probes for different types of value. The interview guide was assessed part way though to examine the types of responses elicited by the different questions. Alphanumeric identities were assigned to each interviewee; the illustrative quotes use these to distinguish between speakers.

\section{Data analysis}

Interviews were audio-recorded and transcribed verbatim by a third party. All interview transcripts were verified prior to coding to ensure accuracy. Coding 
was conducted deductively using NVivo V9 (QSR International), supported by Excel. Data were coded in their original language, and selected French quotes were translated to English for reporting. The coding scheme and codebook aligned with each level of analysis and type of value in the evaluation framework, in keeping with framework analysis approaches (Pope, Ziebland, \& Mays, 2000; Spencer, Ritchie, O'Connor, Morell, \& Ormston, 2014). Specifically, charting for structured, theme-based, deductive analysis allowed the exploration of each type of value and level of analysis, as well as any overlap. Using a framework in Excel highlighted the extent to which the data could be captured within one or multiple parts of the framework, or they did not fit. Pairing this with additional thematic analysis in NVivo allowed for more in-depth learning about the CoP, which may be a common goal of evaluation. Such a directed approach to content analysis with deductive coding was useful to validate or extend the evaluation framework (Hsieh \& Shannon, 2005).

The lead author carried out the coding, followed by co-coding and discussion with second reviewers from the team. Notes and discussion of the processes focused on the challenges of coding according to the evaluation framework and possible modifications to the latter. Using multiple coders with review and discussion allowed for an assessment of whether the concept within the evaluation framework could be applied to the qualitative data. Discussions also included being explicit about potential "biases" in light of positionality.

\section{VALUES GENERATED}

Respondents described a full range of values, generally corresponding well to the types and levels of the evaluation framework (see Table 1 for illustrative, short quotes). In creating Table 1, there were many examples to draw upon for motivation and participation, relational value, knowledge and cognitive value, and learning value. Although many quotes describe a value generated, some represent a particular value not being achieved, particularly for realized value (see examples below). As we move to the right of the evaluation framework, the values are more long-term and distal, less in CoPEH-Canada's sphere of direct control or influence (Montague \& Porteous, 2013), which translated to fewer examples available in the data.

Motivation to participate in $\mathrm{CoPEH}$-Canada included frustration with context or structures external to COPEH-Canada, where CoPEH-Canada, or ecohealth approaches generally, provided a way to work towards addressing issues. Individual and collective-level relational value was a key value produced by $\mathrm{CoPEH}$-Canada. Relational value was frequently discussed in the interviews and was described as satisfying and important by several members. Knowledge and cognitive value, and learning value, were also important to study participants. Respondents made connections between relationships in CoPEH-Canada and the learning that resulted.

Intangible value at the individual level included increased confidence and a sense of validation. Some of the intangible value could be connected to collective 


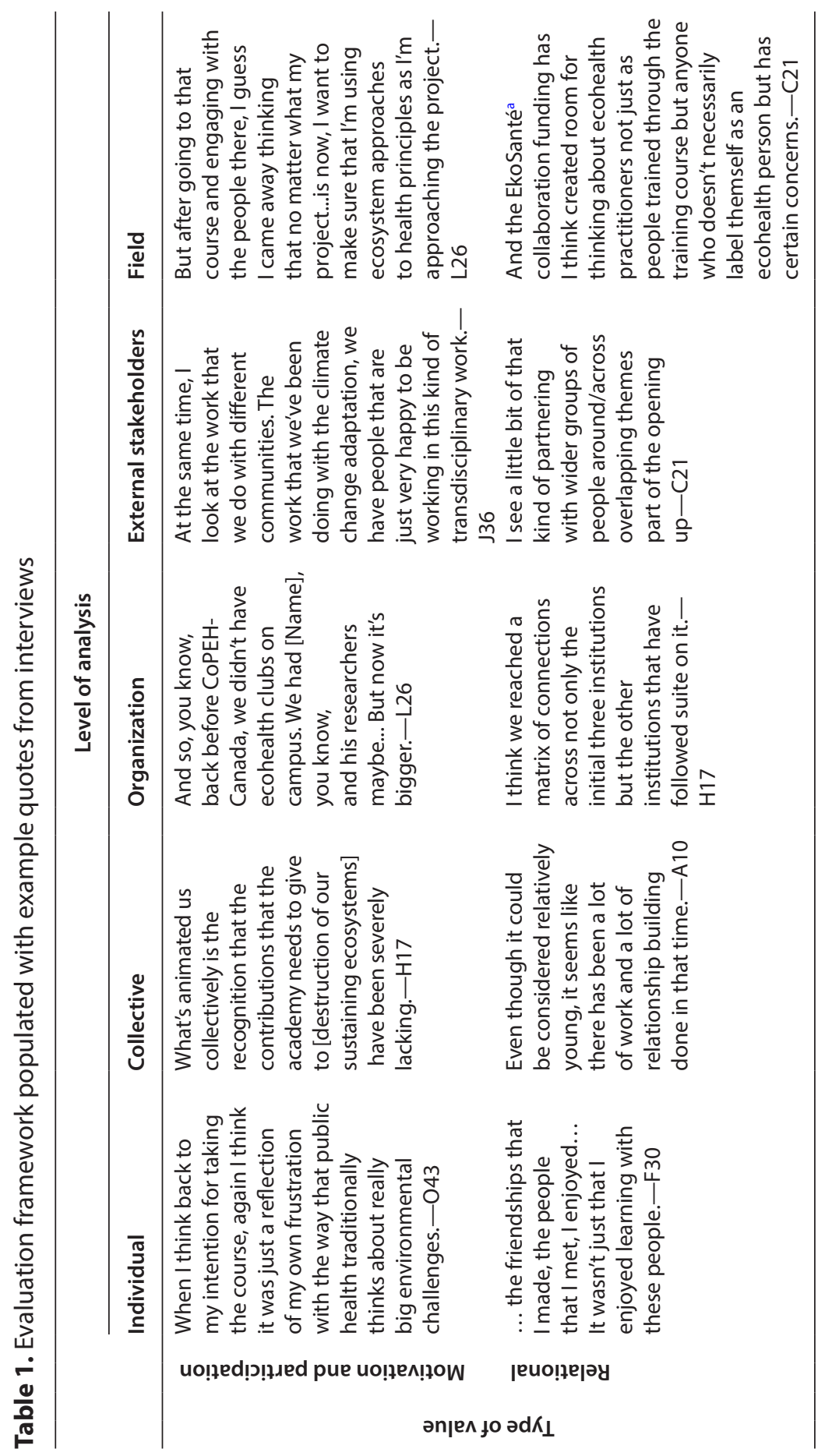




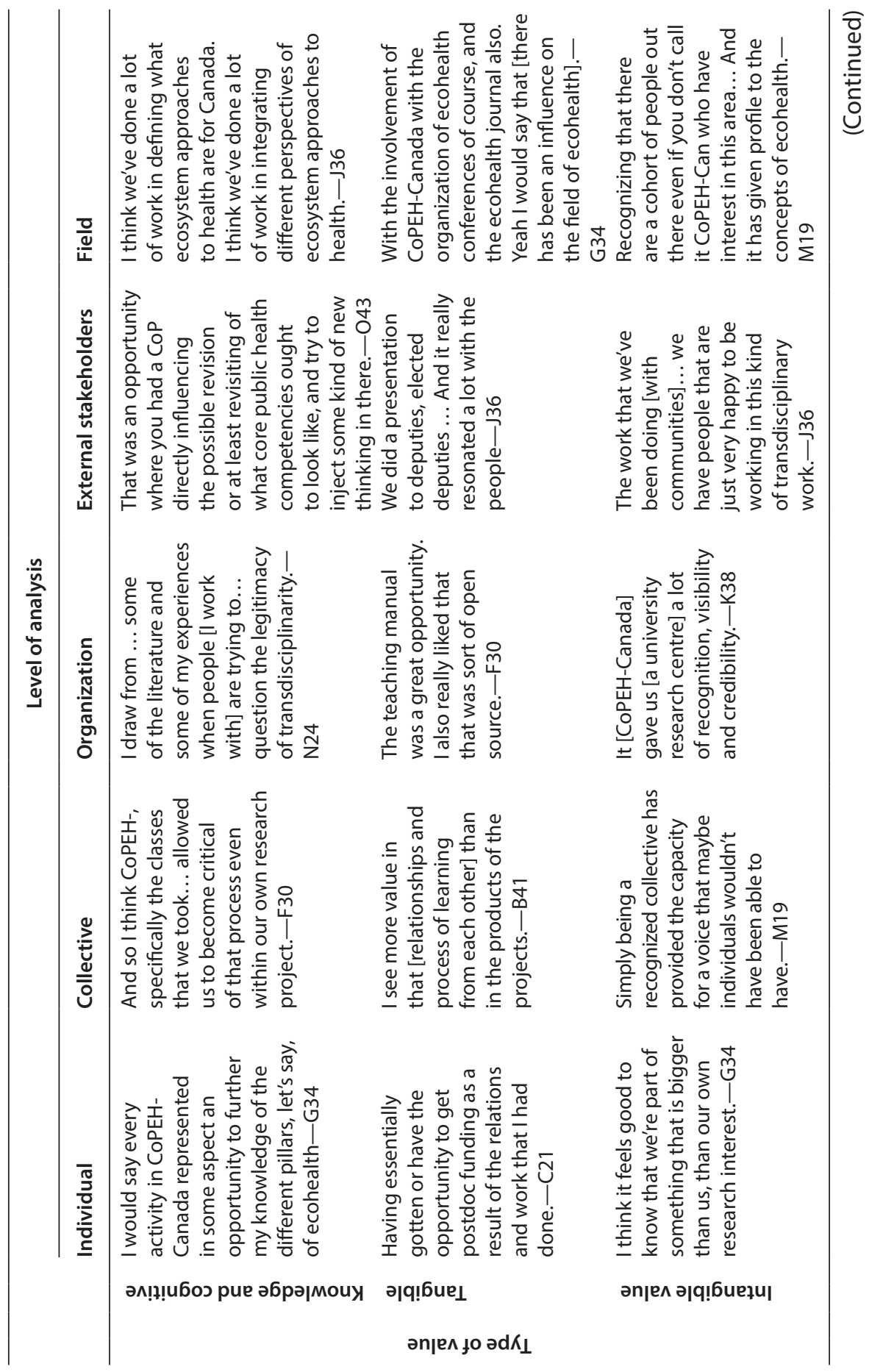




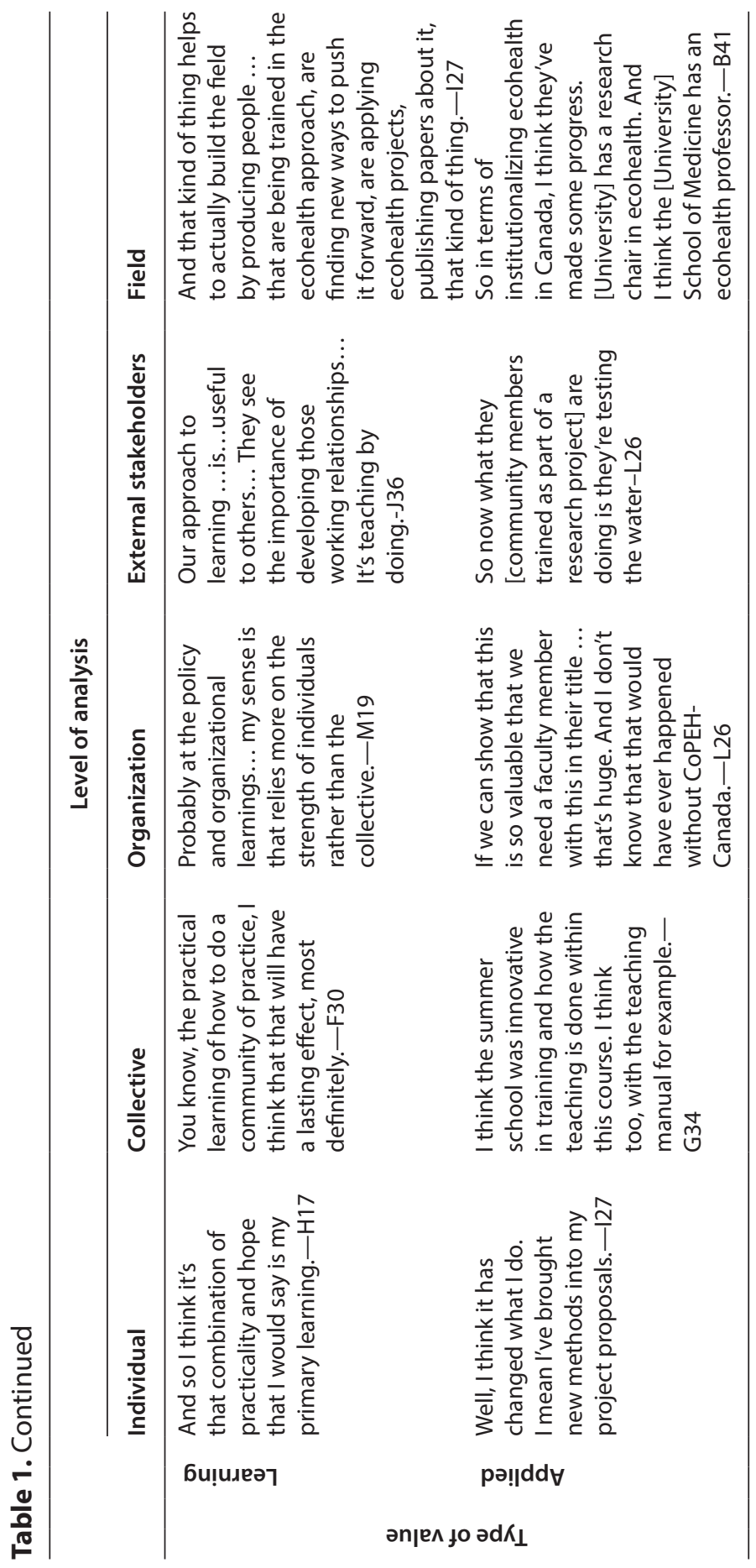




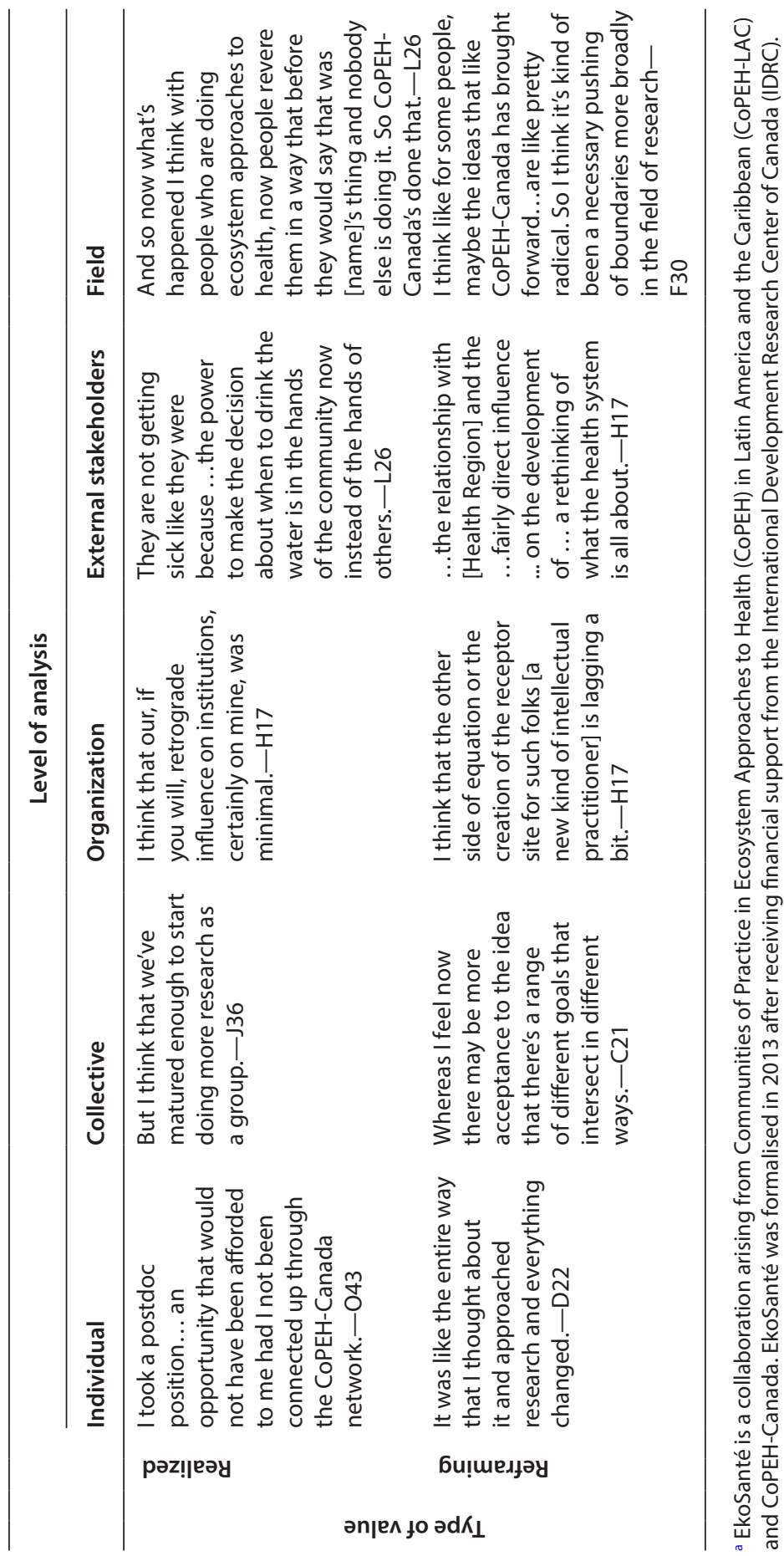


relational value. While examples of tangible value were provided (e.g., the CoPEHCanada teaching manual [McCullagh et al., 2012] and publications), some members suggested that this was not as important as other types of value: "So it wasn't like one specific event or one tangible outcome. It was more about, I guess, the learning process for me" (D22). Among examples of changes in practice (applied value), most notable were changes in approaches to how research was conducted, or the adoption of ecohealth approaches to research. For realized value, members reported changes in career-related performance. At the collective level, realizedvalue examples included engaging in interdisciplinary processes and taking new approaches to organizing workshops. Participants described changes at the individual and collective levels, about developing as a person or maturing as a group.

Respondents found that value for members' organizations included nonCoPEH Canada individuals (e.g., other employees) being introduced to ecohealth approaches, seeking out partnerships with CoPEH-Canada members, and applying ecohealth approaches to their work. Additionally, courses for different universities were developed using innovative teaching and workshop approaches. Respondents also provided examples of relational value, knowledge and cognitive value, and applied value for external stakeholders, such as regional health authorities. Communities that were target populations of members' ecohealth research were reported to experience knowledge and cognitive value, applied value, and realized value of improved health.

Regarding the field level, respondents offered examples of pushing the boundaries or ideas of the field and contributing to the cohesion and legitimacy of ecohealth. Many of the values for the field overlapped with values in other levels of analysis; for example, ecohealth having a stronger presence (faculty, student clubs) at universities, and health regions and non-governmental organizations (NGOs) incorporating ecohealth concepts.

\section{EVALUATION FRAMEWORK REFLECTIONS AND REFINEMENTS}

Challenges regarding the evaluation framework's application allowed us to identify aspects of the framework that could be clarified, expanded, and re-organized. These are reported here and in a revised template (Table 2) of the evaluation framework with accompanying definitions. In the revised template, we re-ordered the columns in the framework to locate values that share similarities (e.g., knowledge and learning and identity).

\section{Activities}

Activities of and events organized by the CoP did not have an obvious place within the framework, as they did not fit the original definition of tangible value. In the Value Creation Framework (Wenger et al., 2011), these would be considered immediate value; however, that categorization is considered problematic because the events can be the results of collaborative efforts and not just a source of satisfaction or of building connections. This was an illustrative example: 
realize that there's not really a distinction" (F30). Hence, in the revised framework, we included identity development as part of learning value.

\section{Knowledge versus learning}

Another significant challenge in applying the evaluation framework was the distinction between knowledge and cognitive value, and learning value. The original distinction was created to address the importance of these values to CoPs and to create a distinction between processes and outcomes of learning. Learning processes can be individual or social, and social learning processes can have effects on both the individual and collective levels (Reed et al., 2010). The distinction of process and outcomes is both familiar and useful for evaluators; however, the distinction is confusing and counter to $\mathrm{CoP}$ and situated learning theories. Situated learning theory proposes that knowledge is not just acquired and emphasizes the social-cultural dynamic through considerations of participation, identity construction, and practice (Handley, Sturdy, Fincham, \& Clark, 2006). Despite the substantial overlap of process and outcomes, we propose that they remain as two distinct types of value within the framework, but with renaming and clarification of the definition. Knowledge value refers to knowledge and skill (both explicit and tacit knowledge) regarding the domain and practice. In contrast, learning and identity value refers to learning how to learn and work collaboratively and is process-oriented (including reflective processes).

\section{Reframing value}

Similarly, there was not a well-defined boundary between learning value and reframing value. As learning is a constant process of negotiating within CoPs, the threshold at which something is considered a reframing is not clear. To help distinguish this, we looked at the similarities between social learning and loop-learning theory. Reframing has been associated with double-loop learning, which refers to revisiting assumptions (e.g., about cause-effect relationships), while transforming has been associated with triple-loop learning (Pahl-Wostl, 2009), which refers to reconsidering underlying values, beliefs, and world views. Triple-loop learning has been conceived as a form of organizational learning (Tosey, Visser, \& Saunders, 2012). The revisiting of assumptions within a value-normative framework and a reconsideration of underlying values, beliefs, and worldviews (triple-loop learning) are important to capture, as are the changes that have resulted from such learning. Therefore, we propose renaming and expanding the value to reframing and transformative value, defined as the reconsideration of learning imperatives as a result of learning itself, a redefinition of success, or a fundamental change. This alteration also better aligns with Wenger-Trayner's (2014) advancement of the Value Creation Framework. Value related to reflective practices would be captured in both learning and identity value and reframing and transformative value.

Additionally, Wenger et al. (2011) highlight that this value can be about a transformation or leaving behind existing structures; this was expressed by several 
members. In response to a question about possible benefits, one respondent said: "I guess my broadest answer is I feel like it's made me who I am. You know, it's kind of as big as that" (N24). This quote illustrates a sense of becoming through participation, a personal transformation, although the respondent does not speak of a new definition of success.

\section{Connections between learning and other types of value}

The examples related to learning value highlighted the connections with other types of value. Respondents made connections between relationships in CoPEHCanada and the learning that resulted, consistent with key concepts of CoP theory, such as social and situated learning. They also talked about the structure that COPEH-Canada provides for individuals to exchange ideas and opportunities for social learning. The following quote provides an example: "And I guess being able to see what different people in different places are thinking and situate my own practice and theorizing in relation to that" (C21). The link between relational value and learning value was shown by a member's quote that highlights psychological safety, which is described as being important for knowledge sharing (Zhang, Fang, Wei, \& Chen, 2010), learning (Johnson, 2001), and CoP sustainability (McCormack et al., 2017). In response to a question about the most satisfying part of participating in CoPEH-Canada, one respondent highlighted "the ability to be able to think outside of the box and to be comfortable" (J36). While we are proposing that overlap between values and the associated analysis codes is addressed by adding clarity to the definitions, other overlaps are further opportunity for learning about the mechanisms that promote or hinder values.

\section{DISCUSSION}

\section{Limitations}

Several limitations are notable in this application of the evaluation framework and its assessment. Although the interviews provided rich insights about the values produced, the number and variety of interviewees were limited. Although we might have achieved "code saturation," with a full range of thematic issues identified, we may not have reached "meaning saturation," that is, providing a rich understanding of issues (Hennink et al., 2017). Inclusion of non-members (e.g., representatives from organizations, people who participate in the field of ecohealth but are not CoPEH-Canada members) could have provided a better sense of whether the evaluation framework captured values at the organization, field, and external stakeholder levels. Furthermore, additional sources of data could have extended the assessment of the framework. For example, document review could have contributed examples of policy change, relevant to applied value at the external stakeholder level, or challenges in achieving policy change (Brisbois et al., 2017). 
Using the framing of value rather than, for example, process and outcomes probably influenced what we assume is a bias toward a positive framing. This bias was only partially mitigated by prolonged engagement and attention to interview guides. Interviewees tended to express or share positive aspects of their participation, underrepresenting the tensions within the $\mathrm{CoP}$ and areas for improvement within CoPEH-Canada.

Further, as we examined only a single case example, it was not possible to fully identify the sources of discrepancy between the data and the framework. For example, if a value was not well demonstrated, it might point to improvements needed in the interview guide or evaluation approach, rather than a demonstration that this value was not generated by $\mathrm{CoPEH}$-Canada or that a particular aspect should be removed from the evaluation framework.

\section{Strengths}

The evaluation framework proved useful in a range of ways: to orient the CoP evaluation, to develop the interview guide, to structure the deductive analysis, and to report and display data. Through these applications, the evaluation framework fulfilled its role as a comprehensive tool for categorizing the values generated by an extra-organizational CoP. Using qualitative methods was appropriate to this first application of the framework, as it might be to assessing the application of other new conceptually derived frameworks to CoP, network, or other program evaluations. Reflecting on the application provided the opportunity for sharing challenges confronted, clarifying concepts, and making refinements to the framework and relevant definitions.

A methodological strength was acknowledging and sampling a range of different roles within CoPs. Traditionally, CoP roles have focused on "newcomer" (novice) and "old-timer" (expert), and the progression from newcomer to oldtimer or full participant (Lave \& Wenger, 1991). This dichotomous view stems from Lave and Wenger's (1991) CoP theory development with apprenticeship. Yet it is not helpful when people who have different forms of expertise and ranges of prior experience join the CoP (Fuller, Hodkinson, Hodkinson, \& Unwin, 2005), as in CoPEH-Canada and other transdisciplinary CoPs. Speaking with a variety of members provided opportunities for greater breadth in examples of values.

Furthermore, qualitative data-collection strategies that allowed for flexibility in the interviews provided further insight concerning the values in the framework, the relative importance of different levels, and ways for CoPs to extend the value created. The data could also be used to explore the possible mechanisms related to the value generated, particularly at the individual and collective levels. Although not explicitly a part of the evaluation framework, mechanisms are ways of generating (or hindering) value, connecting two or more types of value across levels of analysis. For example, the description of value generated here can foster an understanding of the multiple pathways of generating value and the "virtuous circles" involved in CoPs. This virtuous circle is where, as Thompson (2005, p. 152) describes it, "the more people participate, the more they learn, and the more 
they identify with and become prominent within a group, becoming more motivated to participate even further, and so on."

\section{FUTURE DIRECTIONS AND APPLICATIONS}

Future research applications of the evaluation framework to different kinds of extra-organizational CoPs and networks could expand the interview guide to probe why particular values might not be generated, including the influence of context(s) in which the CoP is embedded. Depending on mandate, datacollection sources could be broadened to include non-CoP members and better inform analysis of value generated at the organizational, external stakeholder, and field levels. Depending on resources, the primarily qualitative approach could be extended to mixed methods approaches, similar to that applied in evaluating a rehabilitation CoP (Gauvreau, Le Dorze, Kairy, \& Croteau, 2019) and radiation treatment program CoP (Glicksman et al., 2019), or quantitative indicators can show the different types of value created and for whom. More micro-level tools can be used for data collection and analysis. For example, Nistor, Daxecker, Stanciu, and Diekamp (2015) provide a questionnaire that addresses elements of individual and collective relational value associated with acceptance of knowledge sharing. Reflection on and analysis of uses of the framework in more research-oriented evaluations could also address questions such as "What are the best techniques for understanding and measuring each level value?" The measurement question could be developed to quantitative tools to capture such value, just as existing logic-model approaches track numeric indicators.

The evaluation framework is generalizable in that it can be applied to CoPs with different domains, practices, and characterizations of success. While the evaluation framework has multiple levels and types of value, the intention is not to imply that all aspects of the evaluation framework should be covered in all evaluations. When applying the framework to a particular CoP, we suggest tailoring the framework to its characteristics and needs. With tailoring, the framework can, therefore, be used by extra-organizational CoPs, other CoPs, or even other forms of networks that communities are engaging in evaluation.

Practically, evaluators, researchers, and CoP members can use the revised evaluation framework to orient stakeholders early in a CoP's development and learn about (their) CoPs to facilitate the generation of positive value (Probst $\&$ Borzillo, 2008). The multi-level approach is appropriate to evaluations of other complex interventions; however, if a $\mathrm{CoP}$ is only with an organization, the external stakeholders and field levels may be less critical. The semi-structured interview guide is another resource (available from the authors) for data collection. Evaluations could focus on particular parts of the framework or types of value. For example, a newer $\mathrm{CoP}$ might be more likely to generate value toward the left-hand side of the framework, because getting applied or reframing value may need more time. Making such applications publicly available would substantially increase the literature available on the impacts of CoPs. 


\section{REFERENCES}

Amin, A., \& Roberts, J. (2008). Knowing in action: Beyond communities of practice. Research Policy, 37(2), 353-369. https://doi.org/10.1016/j.respol.2007.11.003

Barbour, L., Armstrong, R., Condron, P., \& Palermo, C. (2018). Communities of practice to improve public health outcomes: A systematic review. Journal of Knowledge Management, 22(2), 326-343. https://doi.org/10.1108/jkm-03-2017-0111

Brisbois, B. W., Delgado, A. B., Barraza, D., Betancourt, Ó., Cole, D., Gislason, M., ... SaintCharles, J. (2017). Ecosystem approaches to health and knowledge-to-action: Towards a political ecology of applied health-environment knowledge. Journal of Political Ecology, 24(1), 692-715. https://doi.org/10.2458/v24i1.20961

Brown, J. S., \& Duguid, P. (1991). Organizational learning and communities-of-practice: Toward a unified view of working, learning, and innovation. Organization Science, 2(1), 40-57. https://doi.org/10.1287/orsc.2.1.40

Buckley, S., \& Du Toit, A. (2010). Academics leave your ivory tower: Form communities of practice. Educational Studies, 36(5), 493-503. https://doi.org/10.1080/030556 90903425532

Charron, D. F. (Ed.). (2012). Ecohealth research in practice: Innovative applications of an ecosystem approach to health. New York, NY: Springer.

Chouinard, J. A. (2013). The case for participatory evaluation in an era of accountability. American Journal of Evaluation, 34(2), 237-253. https://doi.org/10.1177/1098214013478142

Contandriopoulos, D., Larouche, C., \& Duhoux, A. (2018). Evaluating academic research networks. Canadian Journal of Program Evaluation, 33(1), 69-89. https://doi. org/10.3138/cjpe.42159

Fuller, A., Hodkinson, H., Hodkinson, P., \& Unwin, L. (2005). Learning as peripheral participation in communities of practice: A reassessment of key concepts in workplace learning. British Educational Research Journal, 31(1), 49-68. https://doi.org/ 10.1080/0141192052000310029

Gauvreau, C. A., Le Dorze, G., Kairy, D., \& Croteau, C. (2019). Evaluation of a community of practice for speech-language pathologists in aphasia rehabilitation: A logic analysis. BMC Health Services Research, 19(1). https://doi.org/10.1186/s12913-019-4338-0. Medline:31358002

Glicksman, R., Ang, M., Murray, E., Simniceanu, C., Lockhart, E., Gilbert, J., ... Warde, P. (2019). Improving quality of radiation therapy care across Ontario using a community-of-practice approach. Practical Radiation Oncology, 9(2), e242-e248. https://doi.org/10.1016/j.prro.2018.10.017. Medline:30447404

Handley, K., Sturdy, A., Fincham, R., \& Clark, T. (2006). Within and beyond communities of practice: Making sense of learning through participation, identity and practice. Journal of Management Studies, 43(3), 641-653. https://doi.org/10.1111/j.14676486.2006.00605.x

Hennink, M. M., Kaiser, B. N., \& Marconi, V. C. (2017). Code saturation versus meaning saturation: How many interviews are enough? Qualitative Health Research, 27(4), 591-608. https://doi.org/10.1177/1049732316665344. Medline:27670770

Hsieh, H.-F., \& Shannon, S. E. (2005). Three approaches to qualitative content analysis. Qualitative Health Research, 15(9), 1277-1288. https://doi.org/10.1177/1049732305276687. Medline:16204405 
Johnson, C. M. (2001). A survey of current research on online communities of practice. The Internet and Higher Education, 4(1), 45-60. https://doi.org/10.1016/s10967516(01)00047-1

Kothari, A., Boyko, J. A., Conklin, J., Stolee, P., \& Sibbald, S. L. (2015). Communities of practice for supporting health systems change: A missed opportunity. Health Research Policy and Systems, 13. https://doi.org/10.1186/s12961-015-0023-x. Medline: 26208500

Lave, J., \& Wenger, E. (1991). Situated learning: Legitimate peripheral participation. Cambridge, England: Cambridge University Press.

Lee, J., Suh, E.-H., \& Hong, J. (2010). A maturity model based CoP evaluation framework: A case study of strategic CoPs in a Korean company. Expert Systems with Applications, 37(3), 2670-2681. https://doi.org/10.1016/j.eswa.2009.08.011

McCormack, C., Kennelly, R., Gilchrist, J., Hancock, E., Islam, J., Northcote, M., \& Thomson, K. (2017). From dream to reality: Sustaining a higher education community of practice beyond initial enthusiasm. In J. McDonald \& A. Cater-Steel (Eds.), Communities of practice: Facilitating social learning in higher education (pp. 599-622). Singapore: Springer.

McCullagh, S., Berbes-Blasquez, M., Feagan, M., Houle, K., Hunter, B., Lemire, M., ... Surette, C. (2012). Teaching manual: Ecosystem approaches to health teaching resources. Canadian Community of Practice in Ecosystem Approaches to Health (CoPEHCanada). Retrieved from http://www.copeh-canada.org/en/teaching-manual.html

McKellar, K. A. (2019). Evaluating extra-organizational communities of practice (Doctoral dissertation). University of Toronto, Toronto, ON. Retrieved from http://hdl.handle. net/1807/95912

McKellar, K. A., Pitzul, K. B., Yi, J. Y., \& Cole, D. C. (2014). Evaluating communities of practice and knowledge networks: A systematic scoping review of evaluation frameworks. EcoHealth, 11(3), 383-399. https://doi.org/10.1007/s10393-014-0958-3. Medline:25023411

Montague, S., \& Porteous, N. L. (2013). The case for including reach as a key element of program theory. Evaluation and Program Planning, 36(1), 177-183. https://doi. org/10.1016/j.evalprogplan.2012.03.005. Medline:22607710

Nistor, N., Daxecker, I., Stanciu, D., \& Diekamp, O. (2015). Sense of community in academic communities of practice: Predictors and effects. Higher Education, 69(2), 257-273. https://doi.org/10.1007/s10734-014-9773-6

Pahl-Wostl, C. (2009). A conceptual framework for analysing adaptive capacity and multi-level learning processes in resource governance regimes. Global Environmental Change, 19(3), 354-365. https://doi.org/10.1016/j.gloenvcha.2009.06.001

Parkes, M. W., Charron, D. F., \& Sánchez, A. (2012). Better together: Field-building networks at the frontiers of ecohealth research. In D. F. Charron (Ed.), Ecohealth research in practice (pp. 231-253). New York, NY: Springer

Parkes, M. W., Saint-Charles, J., Cole, D. C., Gislason, M., Hicks, E., Le Bourdais, C., ... Canadian Community of Practice in Ecosystem Approaches to Health Team. (2017). Strengthening collaborative capacity: Experiences from a short, intensive field course on ecosystems, health and society. Higher Education Research \& Development, 36(5), 1031-1046. https://doi.org/10.1080/07294360.2016.1263937 
Pope, C., Ziebland, S., \& Mays, N. (2000). Analysing qualitative data. In C. Pope \& N. Mays (Eds.), Qualitative research in health care (vol. 3, pp. 63-81). Hoboken, NY: Blackwell.

Probst, G., \& Borzillo, S. (2008). Why communities of practice succeed and why they fail. European Management Journal, 26(5), 335-347. https://doi.org/10.1016/j. emj.2008.05.003

Reed, M. S., Evely, A. C., Cundill, G., Fazey, I., Glass, J., Laing, A., ... Stringer, L. C. (2010). What is social learning? Ecology \& Society, 15(4), response 1. https://doi.org/10.5751/ es-03564-1504r01

Schwandt, T. A. (2003). "Back to the rough ground!” Beyond theory to practice in evaluation. Evaluation, 9(3), 353-364. https://doi.org/10.1177/13563890030093008

Spencer, L., Ritchie, J., O'Connor, W., Morrell, G., and Ormston, R. (2014). Analysis in practice. In J. Ritchie, J. Lewis, C. McNaughton Nicholls, \& R. Ormston (Eds.), Qualitative research practice: A guide for social science students and researchers (pp. 295-346). London, England: National Centre for Social Research (UK) and Sage Publications.

Teddlie, C., \& Yu, F. (2007). Mixed methods sampling: A typology with examples. Journal of Mixed Methods Research, 1(1), 77-100. https://doi.org/10.1177/1558689806292430

Thompson, M. (2005). Structural and epistemic parameters in communities of practice. Organization Science, 16(2), 151-164. https://doi.org/10.1287/orsc.1050.0120

Tosey, P., Visser, M., \& Saunders, M. N. K. (2012). The origins and conceptualizations of "triple-loop" learning: A critical review. Management Learning, 43(3), 291-307. https://doi.org/10.1177/1350507611426239

Wenger, E. (1998). Communities of practice: Learning, meaning, and identity. Cambridge, England: Cambridge University Press.

Wenger, E., McDermott, R., \& Snyder, W. M. (2002). Cultivating communities of practice: A guide to managing knowledge. Boston, MA: Harvard Business School Press.

Wenger, E., Trayner, B., \& de Laat, M. (2011). Promoting and assessing value creation in communities and networks: A conceptual framework. Heerlen, Netherlands: Open Universiteit, Rood de Moor Centrum. Retrieved from http://wenger-trayner.com/ wp-content/uploads/2011/12/11-04-Wenger_Trayner_DeLaat_Value_creation.pdf

Wenger-Trayner, B. (2014). World Bank report and recommendations: Learning partnerships in the program for capacity building to strengthen good financial governance in Southern and Eastern Africa. Retrieved from http://sadcopac.publicaccountscommittees. wikispaces.net/file/view/14-11-21+WB+report+SADCOPAC+EAAPAC.pdf

Zhang, Y., Fang, Y., Wei, K.-K., \& Chen, H. (2010). Exploring the role of psychological safety in promoting the intention to continue sharing knowledge in virtual communities. International Journal of Information Management, 30(5), 425-436. https://doi. org/10.1016/j.ijinfomgt.2010.02.003

\section{AUTHOR INFORMATION}

Kaileah A. McKellar is an assistant professor (status) at the Institute of Health Policy, Management and Evaluation at the University of Toronto. She has worked in program evaluation and performance measurement in multiple health sectors. Her current interests 
are in theory-based evaluation, health systems research, and knowledge translation. This article presents part of her $\mathrm{PhD}$ research on evaluating extra-organizational communities of practice.

Johanne Saint-Charles is the director of l'Institut santé et société and a professor in the Département de communication sociale et publique at l'Université du Québec à Montréal.

Whitney Berta is a professor with the Institute of Health Policy, Management and Evaluation at the University of Toronto. Her interests are in organizational behavior and organizational learning, with a particular focus on institutional long-term care.

Rhonda Cockerill is a professor emerita and former director at the Institute of Health Policy, Management and Evaluation at the University of Toronto. She is a credentialed evaluator, with particular interests in evaluation of community-based programs and performance indicators.

Donald C. Cole is an emeritus professor and a physician, with a master's in health research methods and post-doctoral studies in ecosystem approaches to health. During over 35 years of practice, research, capacity strengthening, and policy work in Canada and lower- and middle-income countries, he has emphasized multi-stakeholder action research processes to change socio-ecological conditions to improve physical and mental health. He mentors, conducts research, and provides service as a consultant. 


\section{APPENDIX: DEFINITIONS OF FRAMEWORK TERMS}

\section{Levels of Analysis}

Individual: This represents the value for individual members (people) of the CoP.

Collective: This represents the CoP as a whole or unit. There are both individual and collective manifestations in the motivations and processes of CoPs, so it follows that the outcomes of participation also occur at the individual and collective level. Early literature in CoPs promotes the collective as a unit of analysis, and Wenger (1998) specifies that joint enterprise is considered a collective product.

Organization: This represents the firms, institutes, or organizations to which members of the CoPs belong (as employees or other affiliation). Some organizations may fund or support extra-organizational CoPs, while others may have no direct involvement.

External Stakeholder: The level of external stakeholder is unique because it can represent individuals, organizations, and/or target populations of the CoP. Stakeholders are actors (persons or organizations) with a vested interest, either in the effective operation of the CoP, their domain, their practice, or the values generated. The distinction here is that they are external to the CoP.

Field: The field is related to the subject, issue, or topic in which members share an interest or passion. The field is composed of both codified knowledge and emergent knowledge. It is represented in the ongoing work of researchers and practitioners active in the field and tacit knowledge held by individual researchers and practitioners. The field is related to the concept of domain for a CoP, where the latter is subsumed within the former. It can be similar to profession.

\section{Types of Value}

Motivation and Participation: This refers to the motivational responses as a consequence of engaging with the CoP. These can be goals and aspirations, or positive feelings from participation, as well as sources of motivation to participate.

Relational: This includes structural (e.g., connections, meeting a person) and relational aspects (e.g., quality of relationships, trust).

Knowledge: This includes knowledge and skill regarding the domain and practice. It can be both tacit and explicit knowledge. This is related to shared meaning and understanding that individuals or groups have with one another. 
Learning and Identity: The learning aspect of this value is process-oriented (including reflective processes) and relates to learning how to learn and work collaboratively. It also includes changes in identity that result through negotiated meaning with the CoP.

Intangible: This refers to intangible assets that are not elsewhere captured. Examples include status of an individual, the reputation of the CoP, its collective voice or the salience of the domain.

Tangible: Tangible assets are similar to the shared repertoire of the CoP. These can include documents, tools, procedures, and methods.

Applied: This represents changes in practice that come from the application of the above-listed types of value.

Realized: These are the results of the CoP and, in particular, of applied value or behaviour change. This represents value that is more traditionally considered outcomes in evaluation.

Reframing and Transformative: The reconsideration of learning imperatives a result of the learning itself, a redefinition of success or a fundamental change. 